\title{
Balkanologie
}

Balkanologie Revue d'études pluridisciplinaires

Vol. IX, n 1-2 | 2005

Volume IX Numéro 1-2

\section{Regan (Krešimir), ur., Hrvatski povijesni atlas (Atlas historique croate)}

Zagreb : Leksikografski Zavod Miroslav Krleža, 2003, 386 p.

\section{Bernard Lory}

\section{(Q) OpenEdition}

\section{Journals}

Édition électronique

URL : http://journals.openedition.org/balkanologie/2005

DOI : 10.4000/balkanologie.2005

ISSN : 1965-0582

\section{Éditeur}

Association française d'études sur les Balkans (Afebalk)

Édition imprimée

Date de publication : 1 décembre 2005

ISSN : 1279-7952

\section{Référence électronique}

Bernard Lory, «Regan (Krešimir), ur., Hrvatski povijesni atlas (Atlas historique croate) », Balkanologie [En ligne], Vol. IX, n 1-2 | 2005, mis en ligne le 14 janvier 2010, consulté le 17 décembre 2020. URL : http:// journals.openedition.org/balkanologie/2005 ; DOI : https://doi.org/10.4000/balkanologie.2005

Ce document a été généré automatiquement le 17 décembre 2020.

(c) Tous droits réservés 


\section{Regan (Krešimir), ur., Hrvatski povijesni atlas (Atlas historique croate)}

Zagreb : Leksikografski Zavod Miroslav Krleža, 2003, 386 p.

\section{Bernard Lory}

\section{RÉFÉRENCE}

Regan (Krešimir), ur., Hrvatski povijesni atlas (Atlas historique croate), Zagreb :

Leksikografski Zavod Miroslav Krleža, 2003, 386 p.

1 Un atlas historique est un outil de travail précieux pour le chercheur. Comprendre les choses simultanément dans leurs dimensions spatiales et temporelles est, en effet, un exercice difficile mais ô combien nécessaire dans une zone aussi compliquée que les Balkans. L'Atlas historique croate est donc hautement bienvenu pour tous ceux qui ont à travailler sur les Balkans occidentaux (Croatie et Bosnie-Herzégovine, dans une certaine mesure Slovénie, Monténégro). Il est particulièrement riche, puisqu'il propose 250 cartes couvrant 8000 ans d'histoire, du paléolithique à nos jours. La présentation fait preuve d'un grand souci de lisibilité, préférant multiplier les cartes plutôt que de les surcharger. Les options principales de l'édition sont de développer l'histoire politique et culturelle de la Croatie. L'histoire politique est fort compliquée, puisque des royaumes et empires différents ont occupé des portions variables du territoire de l'actuelle République de Croatie au cours des siècles. De ce point de vue le Haut Moyen Age est assurément la période la plus difficile à traiter. Une attention particulière est accordée au découpage administratif interne, aux différentes županije, dont les noms et l'extension varie au cours des siècles (douze cartes).

2 L'histoire culturelle est longuement développée pour les cultures néolithiques (13 cartes) et de l'âge du bronze (17 cartes). L'implantation des ordres religieux au MoyenÂge et à l'époque moderne, et les divisions ecclésiastiques en générale, y compris pour 
la période récente (sans oublier orthodoxes, uniates et juifs), sont particulièrement développées. Une douzaine de cartes évoquent le patrimoine architectural de chaque époque actuellement préservé sur le territoire de la République de Croatie). Les cartes 248,249 et 250 indiquent de façon très éclairante les fluctuations successives des territoires désignés sous les noms de Croatie, Slavonie et Dalmatie au cours des siècles.

Certains choix éditoriaux sont néanmoins discutables, comme celui d'une vision plutôt statique que dynamique de l'histoire : c'est particulièrement net à propos de la guerre austro-turque de 1683-1699 (Bečki rat), présentée en onze cartes successives qui obligent le lecteur à une sorte de « jeu des sept erreurs " pour trouver les différences entre deux phases consécutives ; une approche plus dynamique, avec des flèches aurait sans doute été plus efficace. J'avoue ne pas trouver la différence entre les cartes 178 (la Croatie en 1822) et 181 (la Croatie en 1867)...

4 Le plus critiquable dans l'ouvrage est sans doute le choix du cadrage géographique : à une quinzaine près, toutes les cartes sont cadrées exactement de la même manière quel que soit le sujet traité. Ce cadrage, entre le $42^{\mathrm{e}}$ et $47^{\mathrm{e}}$ degré de latitude nord, et le $13^{\circ}$ et le $20^{\circ}$ degré de longitude est, découpe une sorte de fenêtre fixe, à travers laquelle toute l'histoire croate est observée. Elle permet d'inclure l'Istrie à l'ouest, le Medjumurje au nord et le Srijem à l'est mais elle ne permet pas de localiser Venise, ni à plus forte raison Vienne ou Budapest. Cette approche croato-centrée est particulièrement discutable pour les cultures néolithiques ou chalcolithiques qui ne sont traitées que pour l'espace de la République de Croatie contemporaine, sans qu'apparaisse parfois même le site éponyme de la culture (p. ex. Vinča), si celui-ci est extérieur à ces frontières. Ce cadrage unique, indiquant tout à la même échelle, ne facilite guère la compréhension des problèmes très localisés (la question de Trieste, carte 217). Les exceptions à ce cadrage uniforme concernent quelques batailles, Dubrovnik, l'insurrection de Matija Gubec dont l'extension en Slovénie est indéniable, ou encore les phénomènes migratoires du XXème siècle.

Ce parti pris de se centrer sur l'espace national est, bien entendu, intenable sur un plan scientifique, ce qui amène l'édition à insérer, en encart dans le coin inférieur gauche, par-ci par-là quelques cartes grandes comme des timbres-poste pour indiquer l'extension de l'Empire byzantin, du Royaume de Hongrie ou de la Double Monarchie. Qu'il y ait un refus de prendre en compte l'espace de la Yougoslavie (la seule représentation qu'on trouve est un petit encart consacré au "chemin de croix » de 1945, carte 216) peut à la rigueur se comprendre mais le rejet de toute approche régionale, et surtout européenne, a quelque chose d'incompréhensible pour un historien français. Comment comprendre l'histoire de la Dalmatie si aucune carte n'indique l'ensemble des possessions vénitiennes en Méditerranée? Ce refus de contextualiser nuit gravement à la crédibilité scientifique de l'ouvrage : souhaite-t-il vraiment à faire comprendre les choses du passé à son lectorat ? La Croatie ne s'insèret-elle pas dans une histoire européenne? Une lecture exclusivement nationale de l'histoire n'est-elle pas en contradiction avec l'Histoire tout court? 